\title{
Load Performances of a PIC Based Speed Governor for Micro Hydro Power Plant
}

\author{
Cemal Yilmaz ${ }^{1}$, İlhan Koşalay ${ }^{2}$, Ömür Binarbaş $1^{1}$, \\ ${ }^{1}$ Gazi University, Technology Faculty, Electrical and Electronics Eng.Dept., Turkey \\ ${ }^{2}$ Ankara University, Engineering Faculty, Electrical and Electronics Eng.Dept. , Turkey
}

\begin{abstract}
Summary: In the study; a micro hydro power plant prototype was designed with a 750 Wcross flow type turbine and a $500 \mathrm{~W}$ generator. Control operations are realized by using a PIC16F877 microcontroller. The voltage frequency obtained from the generator were measured with the zero crossing circuit and transferred to the microcontroller. Using the micro controller, depending on the frequency error, the PWM signal was formed. The PWM signal was applied through the $H$ bridge circuit to the DC motor which drives the setting wing. The rotation movement of the motor was transferred to the setting wing through a threaded rod and a mechanical arm. When setting of the number of turns on the turbine, the value of the frequency of the used $500 \mathrm{~W}$ generator working in conjunction with the turbine could be kept on desired levels. After the design,Loading and load shedding performances of the designed system were examined and discussed.
\end{abstract}

Keywords: hydroelectric power generation, microcontrollers, frequency control

\section{Introduction}

Micro scale hydroelectric systems are commonly used in areas where national energy grids have not reached. Governor systems in their structure are the major part of them. Digital governor systems are the mostly used governor mechanisms nowadays[1].Before implementing of mini or micro hydro power plants, some designer prefer to model and simulate the system. Simulations are based on different models [2]. Some simulations contains dynamic modeling [3] and speed variability [4]. Conventional control methods for frequency stabilization in mini and micro hydro power plants (HPP) generally use PI, PID controllers. In [5], the authors designed a new PID load frequency controller for a single machine infinite bus hydro system. Henderson [6] used electronic load governor for micro hydro power plant ranging from $1 \mathrm{~kW}$ to $5 \mathrm{~kW}$. Electronic Load Governor controlled the dump load in his study. Doolla and his collogues [7] designed a new cost-effective technique for load frequency control by reducing the size of dump load.Salhi et al. [8] designed a fuzzy logic controller for load frequency control in micro hydro power plant. In an another study, Çam [9] compared PI controller with Fuzzy gain scheduled PI controller (FGPI) for frequency control of hydro power system in single and two area plants. The investigation topics related to micro HPP are given in other studies [10, $11]$.

In the implemented study, a prototype of micro hydroelectric power plant which operates in closed loop with cross-flow turbine by using microcontroller was designed.The generated electrical frequency was kept in a specified band interval. The frequency was continuously measured by using zero crossing circuit and sent to a microcontroller. PIC 16F877 was used as a microcontroller. Movement to the adjustable wing of the turbine was given by DC motor and screw shaft system. Two direction motion of the DC motor was provided by application of the Pulse Width Modulation (PWM) signals generated by microcontroller to a motor through $\mathrm{H}$ Bridge. In the system, water flow rate of Cross-flow turbinewere controlled by moving adjustable wing.

\section{Designed system}

Figure1 shows general appearance of the implemented system. In the study, in order to control the adjustable wing, DC motor is used. MOSFET, which is the switching element of the DC motor, was controlled in two directions by $\mathrm{H}$ bridge motor driver circuit. For controlling the speed of the motor control card which utilizes PWM signal from microcontroller, PIC16F877 is employed.H bridge Motor driver circuit formed by MOSFETs ensures the direct current motor works or stops in two directions. Control of the $\mathrm{H}$ bridge circuit is provided by trigger signals generated by microcontroller PIC16F877. In order to bring MOSFET to conduction PC 817 opt coupler was used.In the prototype of the micro HPP, the turbine works with the free fall of the water. There is a 1500 liters water reservoir at the tower of $7 \mathrm{~m}$ high. The upper side of the reservoir water by itself through penstock flows to the turbine. And the water coming out of the turbine is collected at second reservoir located at the ground. The volume of this reservoir is 1000 liters. Specifications of the pump motor are given in the table 1.The electro-mechanical section consists of cross-flow turbine, generator, pulley system and the control mechanism of the adjustable wing. Specifications of the turbine are shown in the table 2. The label values of the used DC motor are shown in the table 3. 


\section{Control section}

PIC 16F877A is main element on the control section. The frequency of the voltage obtained from generator is read with zero crossing circuit and compared with reference value of $50 \mathrm{~Hz}$, PWM signal is generated with respect to the obtained error. By this mechanism, direct current motor is controlled and the frequency of the voltage coming for generator is set to $50 \mathrm{~Hz}$.In order to control the frequency of the generator, number of cycles of the turbine was controlled. Number of cycles of turbine depending on opening and closing condition of the adjustable wing changes with amount and pressure of water applied to a turbine.In the study, control card measured the frequency of the voltage at the output of generator (fo) using zero crossing circuit and compare with the reference $f_{\text {ref }}=50 \mathrm{Hzcontinuously.} \mathrm{According} \mathrm{to} \mathrm{error} \mathrm{between} \mathrm{the} \mathrm{measured} \mathrm{frequency} \mathrm{value}$ and reference value,PWM signal is generated inside the PIC. Using this PWM signal,the opening and closing operation of adjustable wing was performed and was applied to $\mathrm{H}$ bridge circuit which control DC motor.

In control card, there exists a part which gives the system a DC voltage of 5V. A LCD screen for observing the values read from output of generator and coefficient of PID formed by PWM signals is also connected. The start and stop button on the card help to start and stop the system. Lower limit and upper limit buttons are used for the purpose of testing the system in the laboratory. In real life application switches to be connected to terminal which is parallel to lower and upper limit buttons are used to specify the boundaries of movement of adjustable wing. These boundary switchesis helpful to end automatically commands from control card. If there was no these boundary switches, appearance of faults in mechanical systems would be unavoidable. The LED's in the card are used to understand whether its corresponding output is active or not.

During specifying the microcontroller which is going to be used in the application whether the output and input number needed by the PIC and PWM for controlling direct current motor exist or not waschecked. The knowledge which is taken from external environment is the frequency taken from zero crossing circuit. This information is read by interrupt except for port RBO of PIC. The other information is the normal inputs which are connected to limit switches which tell the open or closed state of the adjustable wing. PWM signals weretaken as output of the PIC. PIC 16F877A is the one which easily satisfies these input and output specifications.

According to UCTE criteria minimum instant frequency should not be below $-800 \mathrm{mHz}(49.2 \mathrm{~Hz})$ and maximum instant frequency should not be more than $+800 \mathrm{mHz}(50.8 \mathrm{~Hz})$ [12]. The reference boundary values of frequency used in the PIC program were specified by considering these values.Due to zero crossing circuit,electrical frequencies from the output of the generator were read easily[13]. The transformer used in zero crossing circuit is connected to the output of the generator. The maximum value of voltage obtained from transformer was selected to be 5V.Direction of the DC motor depends on the direction of the voltage. In order to change the direction, the direction of voltage applied to the motor was changed. For this purpose, $\mathrm{H}$ bridge circuit was used. In order to bring MOSFET to conduction PC 817 opt coupler was used.

\section{Application}

While testing of the system starts, the butterfly van on penstock opens and turbine slowly gain speed. In this moment energized control card continuously measures frequency of the generator and measured values are shown on the LCD screen. When the start button on the control card is pressed, in accordance with program codes inside microcontroller implementation of control process starts and frequency of $50 \mathrm{~Hz}$ is kept constant. At this time, generator works empty-no load.To test how the system works when there is a load, the bulbs connected to the output of the generator were entered to a circuit in stages. In every stage, two $60 \mathrm{~W}$ incandescent film lamp was used.

The observed errors on the continuously measured frequency by several processes inside microcontroller generate PWM of the motor. By the help of this PID controlled PWM signals for DC motor is generated.PWM signals generated by the microcontroller and DC motor are operated in both directions in controlled manner. Due to this the position of adjustable wing of the turbine is being changed and frequency of $50 \mathrm{~Hz}$ is kept constant.

\section{Electrical performances at loading condition}

Voltage, current and active power variations for \% 25 loading level; Current variation curve shows that the inrush current is at a low peak current during start up. This current caused medium level voltage droops at the output terminal. It is expected that larger loading level result in higher inrush peak currents. Current and voltage variations reach steady state level nearly in 50 seconds. Different loading levels produce different shapes of current, voltage wave. In the study, only some important ones of them are given.

Figure 2 illustrates voltage, current and active power variations for \% 75 loading level. Current variation curve shows that the inrush current is at a low peak current during start up. This current caused medium level voltage droops at the output terminal. Current and voltage variations reach steady state level nearly in 35 seconds. 


\section{Electrical performances at load shedding condition}

Voltage, current and active power variations for \% 25 load shedding; Current variation curve shows that the current sharply decreases at the beginning of load shedding. This current causes voltage increase at the output terminal for nearly 5 seconds. It is expected that larger load shedding result in higher voltage increase. Current and voltage variations reach steady state level nearly in 55 seconds. Different load shedding levels produce different shapes of current, voltage wave. In the study, only some important ones of them are given.

Figure 3 illustrates voltage, current and active power variations for $\% 75$ load shedding. Current variation curve shows that the current sharply decreases at the beginning of load shedding. This current causes voltage increase at the output terminal for nearly 60 seconds. Current and voltage variations reach steady state level nearly in 35 seconds.

\section{Conclusions}

In this study, closed loop and grid independent prototype of $750 \mathrm{~W}$ cross-flow turbine whose cycle regulations are done by using adjustable wing mechanism is implemented. Movement to an adjustable wing is performed by direct current motor which is controlled by microcontroller by using screw shaft system and mechanical hand. By setting the number of cycles (speed) of the turbine, the number of cycles and frequency of the $500 \mathrm{~W}$ generator which is connected to a turbine is kept at required values. The implemented study shows that this technique is more economical than other micro hydroelectric plant control methods.

The study is performed on cross-flow type turbine. It is possible to apply same control technique to Pelton turbines. With the investment to be made, in the future times implementations of control systems of the micro turbine using microcontrollers will provide more development in the sector and will bring possibility of easily controlling both grid dependent and independent micro HPP. It is also understood that loading and load shedding performances of the designed system is well enough and it has low cost.

\section{References}

[1]. Dalcalı A, Çelik E \& Arslan, S, Design of a microprosser based electronic governer system for micro and mini hydroelectric power systems, Erciyes Üniversitesi Fen Bilimleri Enstitüsü Dergisi, 18 (2012) 130-135. (In Turkish).

[2]. Acakpovi A, Hagan E B \& Fifatin F X, Review of hydropower plant models, International Journal of Computer Applications, 108 (2014) $0975-8887$.

[3]. Marquez J L, Molina M G \& Pacas J M, Dynamic modeling, simulation and control design of an advanced micro-hydro power plant for distributed generation applications, International journal of hydrogen energy 35 ( 2010 ) 5772 - 5777.

[4]. Ansel A \& Robyns B, Modelling and simulation of an autonomous variable speed micro hydropower station, Mathematics and Computers in Simulation, 71 (2006) 320-332.

[5]. Khodabakhshian A \& Hooshmand R, A new PID controller design for auto- matic generation control of hydro power systems, International Journal of Electrical Power and Energy Systems, 32 (2010) 375-82.

[6]. Henderson D, An advanced electronic load governor for control of micro hydroelectric generation, IEEE Transactions on Energy Conversion, 13 (1998) 300-304.

[7]. Doolla S \& Bhatti T S, Load frequency control of an isolated small-hydro power plant with reduced dump load, IEEE Transactions on Power Systems, 21 (2006)1912-1919.

[8]. Salhi I, Doubabi S, Essounbouli N \& Hamzaoui A, Application of multi-model control with fuzzy switching to a micro hydroelectrical power plant, Renewable Energy, 35 (2010) 2071-2079.

[9]. Cam E, Application of fuzzy logic for load frequency control of hydro electrical power plants, Energy Conversion and Management, 48 (2007) 1281-1288.

[10]. Scherer L G \& Camargo R F, Frequency And Voltage Control of Micro Hydro Power Stations Based On Hydraulıc Turbine's Linear Model Applied On İnduction Generators, In IEEE Power Electronics Conference (COBEP), 546-552 July 2011.

[11]. Mackmore C A \& Merryfield F, The Cross-flow Water Turbine ( Engineering Experiment Station Oregon State College Corvalins, USA) 1949

[12]. Bircan M, Updating of frequency control quality of Turkish Electric Power system with UCTE standards in terms of UCTE connection, Proc Dünya enerji konseyi Türk milli komitesi, Türkiye 10. Enerji Kongresi, 2006, 265-273. (in Turkish)

[13]. Ateş M, Design and simulation of power factor measuring circuit with PIC ,M Sc thesis, Yüzüncü Yıl University-Fen Bilimleri Enstitüsü, Turkey, 2009. 


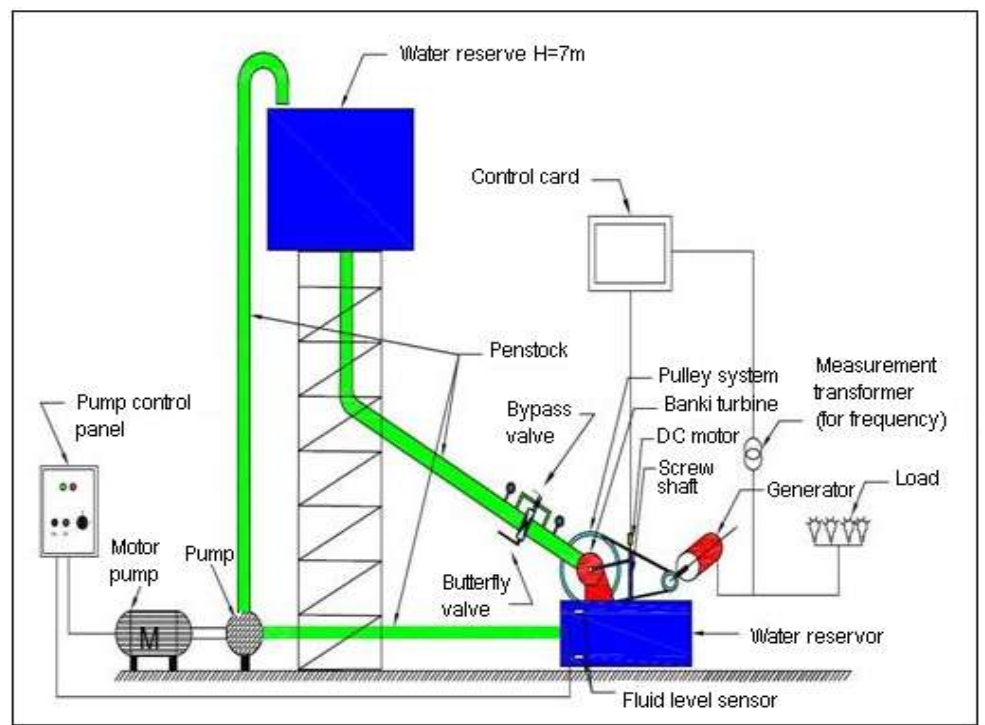

Fig. 1 general appearance of the system which works in closed loop.
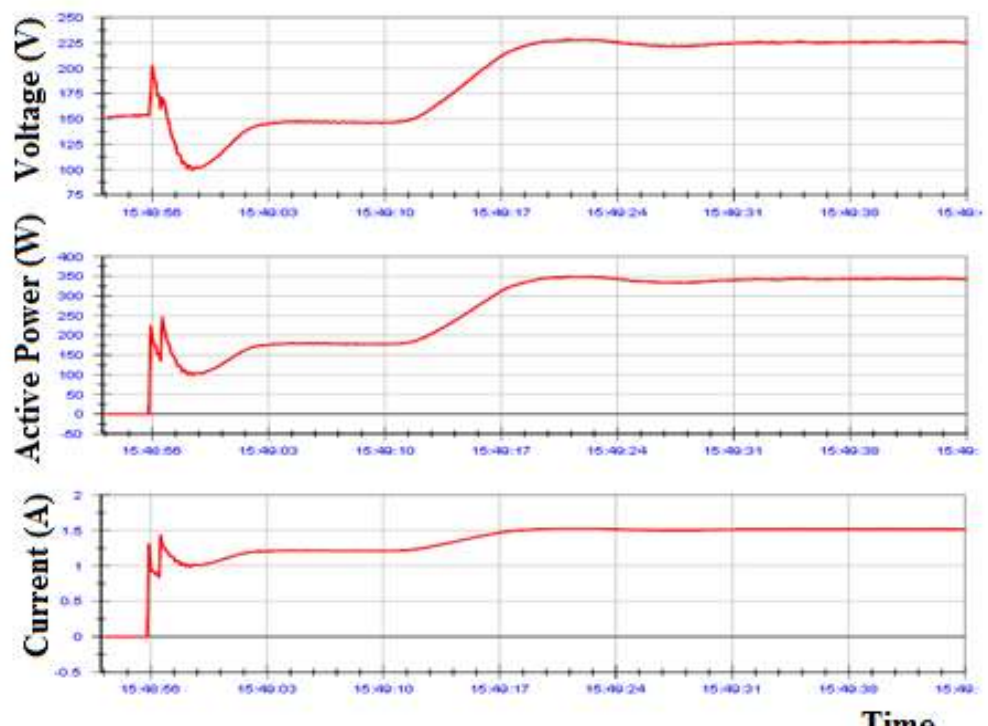

Fig. 2. Loading performance related to $\% 75$ level.

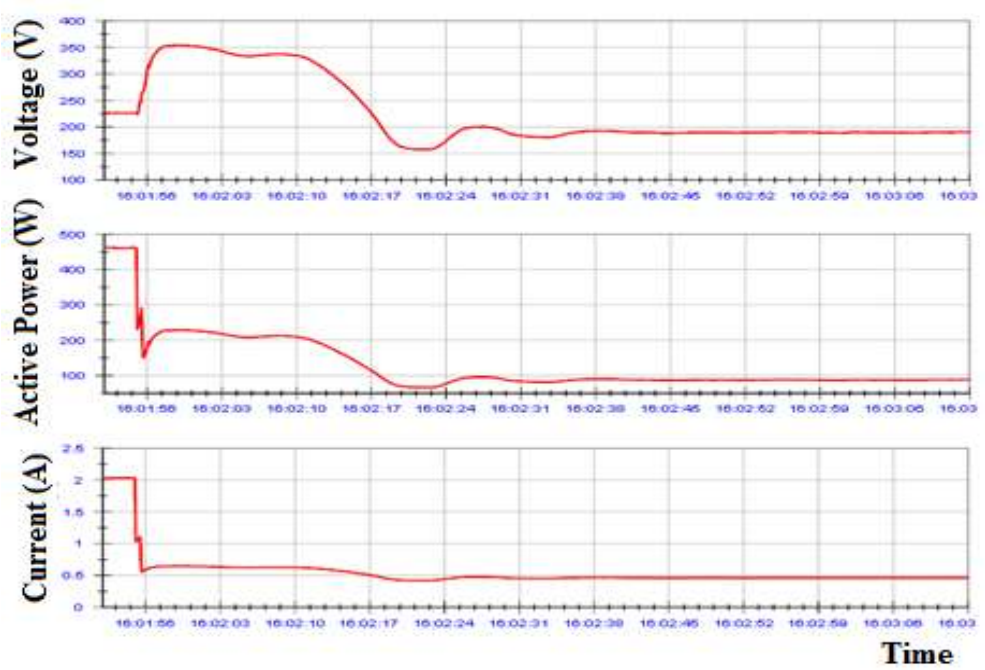

Fig. 3. Load shedding performance related to $\% 75$ levels. 
Table 1 specification of the centrifuge pump

\begin{tabular}{|c|c|}
\hline \multicolumn{2}{|c|}{ Specifications of the pump } \\
\hline Power & $7.5 \mathrm{~kW}$ \\
\hline H max & $16 \mathrm{~m}$ \\
\hline Discharge Q max & $43 \mathrm{~m}^{3} / \mathrm{h}$ \\
\hline cycle & 1400 \\
\hline \multicolumn{2}{|c|}{ Specifications of motor of the pump } \\
\hline Power & $7.5 \mathrm{~kW}$ \\
\hline Cos $\varphi$ & 0.82 \\
\hline voltage & $380 \mathrm{v}$ \\
\hline current & $15.8 \mathrm{~A}$ \\
\hline Frequency & $50 \mathrm{~Hz}$ \\
\hline Cycles & 1430 \\
\hline IP & 55 \\
\hline
\end{tabular}

Table 2 specification of the used cross-flow turbine.

\begin{tabular}{|c|c|}
\hline \multicolumn{2}{|c|}{ Specifications of cross-flow turbine } \\
\hline Power & $0.74 \mathrm{~kW}$ \\
\hline Operation discharge & $15 \mathrm{lt} / \mathrm{s}$ \\
\hline Operation height & $7 \mathrm{~m}$ \\
\hline cycles & $500 \mathrm{rpm}$ \\
\hline
\end{tabular}

Table 3 technical specifications of DC motor.

\begin{tabular}{|c|c|}
\hline Voltage & $24 \mathrm{~V}$ \\
\hline Reduction conversion ratio & $1 / 68$ \\
\hline Cycles & $60 \mathrm{rev} / \mathrm{min}$ \\
\hline Torque & $3 \mathrm{Nm}$ \\
\hline Current & $1.5 \mathrm{~A}$ \\
\hline
\end{tabular}

